\title{
Wine Packaging Aesthetics and Design Based on Chinese Wine Culture
}

\author{
Dapeng Zhou \\ Guangdong Industry Polytechnic \\ Guangzhou, China 510300
}

\begin{abstract}
This paper has analyzed the artistic value of Chinese wine packaging from the perspective of visual aesthetic material, modeling, color and graphic taking the Chinese wine culture as research background. Conclusion has been made and putting forward the creative thought of combining with modern wine packaging design from such perspective of traditional graphic pattern, color succession and innovation, Chinese characters calligraphy elements and traditional utensil modeling to develop modern wine packaging design and carry forward wine culture.
\end{abstract}

Keywords—wine culture; aesthetic; traditional culture; wine packaging design

\section{INTRODUCTION}

The long history of Chinese culture has shaped the longstanding and well-established civilization history of wine. In the five thousand years of civilization, wine culture is a cultural phenomenon that is special yet general, which has infiltrated into various fields of social life, covering every aspects of traditional Chinese culture. Wine culture is closely linked to wine packaging, influencing the design creativity of modern wine packaging directly. Applying traditional culture into wine packaging design and expressing through modern design method is not only the non-material transformation of wine packaging from function to form, but also an important approach for our national wine industry to dig into culture connotation for rising and progress.

\section{DEFINITION OF W INE CUlTuRE}

Wine culture is a unique culture form with wine as material carrier and behavior about drinking wine as center. In broad sense, wine culture contains abundant connotation with a system of its own, including wine-making technology, technique, law system, wine custom, drinking vessel and poetry and essays as well as literary works relating to wine. China has a long history of wine drinking, and the Chinese unique wine culture and custom has been shaped along with improvement of wine making technology and in the long history of wine development. Wine culture mainly reflects in many aspects such as people's faith in wine, traditional wine ethics and morals, influence to national cultural character by wine culture, national wine culture psychology, Chinese wine cultural thinking mode, aesthetic taste, folk language culture, social ideal, philosophy and religion, literature and art, science and technology and so on. One important feature of Chinese culture lies in its ritual color and political color. Rite is the courtesy behavior about wine for reflection of gentle and simple, superior and inferior, older and younger and even the etiquette standard in various occasion, mainly reflect through etiquette behavior, faith behavior, social behavior and entertainment behavior, integrating literature and art, amusing and entertaining, game and wisdom, aesthetic and appreciation as one unity, reflecting diversity, sociability and compatibility of wine culture.

\section{ARtistic Aesthetic V Alue of Chinese Wine PACKAGING}

Wine culture is rooted in traditional Chinese culture, and its materiality and spirituality has determined it shall be the carrier of rite, as well as its role in social activities. People compare their status, value and the relationship of superior and inferior in the society through wine packaging, namely packaging is a commodity of "rituality" that reflects people's social status. Chinese wine culture pays attention to rite and virtue, stresses order, perfect, joyousness, and pursues spirituality. And those cultural concepts become outstanding in terms of wine packaging. Auspiciousness and joyousness manifests cultural connotation. As a result, decorative design of gift box has been the main style of modeling and decoration for wine packaging design.

\section{A. Material Aesthetic Value}

There are plenty of materials for traditional wine packaging, and the inner packaging mainly adopts porcelain, pottery, bamboo, wood, etc., and outer packaging includes such natural materials as fiber, wood, bamboo, rattan, stem, leaf, shell and so on. However, the influence of regional difference of those materials and cognitive level difference have restrained material using of traditional packaging, making the packaging of traditional Chinese white spirit presents obvious regional difference.

\section{B. Modeling Aesthetic Value}

In the packaging of China's white spirit, no matter the container is wooden ware, pottery, bronze ware or lacquer ware, they all have the modeling style of symmetrical, full, solid and full of tension, rendering people a feeling of bold and generous, which is a certain relationship with social aesthetic taste of people's pursuit of perfect and completeness. 


\section{Color Aesthetic Value}

Color also has its unique style in traditional packaging, and this color style has a certain expression of social class. Traditional packaging design also pays special attention to the texture of natural material itself and the expressive force of color without any decoration, indicating the traditional cultural aesthetic taste of "unity of nature and human".

\section{Graphic Aesthetic Value}

Graphic has shaped its unique features in traditional wine packaging as well. Create graphics with implied meaning in accordance with certain kind of beauty based on various auspicious words, graphics and wonderful imagination, making Chinese traditional wine packaging forms a classic national feature.

\section{Design StRategy OF White SpIRIt PackAgING}

Learning and references are the basis for us to make packaging design innovation of white spirit based on Chinese wine culture. China is a country with an ancient civilization and a long-standing cultural history. The accumulation in history has left us abundant artistic resources, enabling us to absorb nutrients from traditional culture and to create packaging design with our own national features. All the traditional artistic forms with classic and traditional Chinese cultural connotation such as folk graphics, emblazonry, New Year Pictures, traditional painting art, sculpture, wax printing and bandhnu and so on can be applied to packaging design as basic plane visual elements. It is the best method to manifest cultural connotation of commodity and national identity by applying Chinese classic traditional graphics and color to the packaging design of white spirit, and a design concept to adapt to localization and nationalization as well.

\section{A. Application of Traditional Graphic and Pattern}

Graphics are important expressive elements of packaging design which originated earlier than words. Graphic symbol is full of reality and symbolic with strong visual impact. There are numerous and various traditional Chinese graphics, bringing about boundless inspiration and design enlightenment to designers. Traditional graphic is the embodiment of a region and national culture, bearing certain implied meaning or connotation. The five-thousand-year civilization of China has generated plenty traditional auspicious graphics. Traditional Chinese graphics is the great creation and result of the intelligent working people of past ages, with unique creation, simple modeling, beautiful colors, exquisite craftsmanship, profound implied meaning, as well as abundant and various forms, such as animal grain, cloud pattern, flying Apsaras, lotus, coils, New Year pictures, embroidery, paper-cuts, shadow puppet, national dress, and facial makeup and so on. Those patterns have strong decorativeness, which are applied to modern design frequently. Those vivid traditional patterns without sense of formality can bring about an atmosphere of freshness and primitive simplicity with strong sense of decoration no matter taking it as shading, main graphic or the decoration for sideline and corner.
Traditional Chinese graphic symbol is applied to packaging design of white spirit by inheriting without copying blindly. Designer shall reintegrate and recreate the traditional design elements to adapt to aesthetic requirements of the target consumers, which is a recreation of traditional graphic symbol. And to select its "form", extend its "meaning" and express its "soul" based on the understanding and selection of traditional graphic symbol. Make the traditional graphic symbol full of characteristics of the times by transforming, refining and exerting some of the modeling elements with modern aesthetic concept and design principle, enabling it to indicate Chinese wine cultural image and brand value of commodity in the integration of tradition and modern.

\section{B. Color Succession and Innovation}

Each country, region or nation has its own unique aesthetic habits and application rule of color. In the long term of lift experience, the ability of judging and feeling commodities based on their packaging colors has been shaped intentionally or unintentionally. As a visual language to express emotion, the artistic charm of color as first visual impression has a profound influence on visual arts. Chinese nation has formed the unique "five-color aesthetic standard" in the long-term production and practice, namely to convey people's emption and will through green, red, yellow, white and black, which is different from western scientific color system with the spirit of Chinese ancient Yin-yang and Fiveelement thoughts. It is a cultural product influenced by ancient original faith, Yin-yang and Five-element, as well as various color aesthetic preference of different dynasties. Warm color is preferred by Chinese nation since ancient times; and red represents joyousness, symbolizing enthusiasm, yellow represents authority, symbolizing wisdom and noble, and golden gives people a feeling of glorious and gorgeous, while orange indicates the meaning of primordial spirit and optimism. In modern packaging design, rational application of traditional color and appropriate expression of cultural connotation of color may render the work national artistic charm. Absolutely, traditional color is not unbreakable, and the design shall be conducted in accordance commodity brand positioning, making breakthrough and innovation in terms of color, enabling it to stand out in competition via unique packaging color. The vivid visual image stands out quickly from the variety of homogenous commodities, leaving consumers profound visual impression, and infusing dynamic fashion for the traditional product of white spirit, rendering the product strong competitiveness.

\section{Application of Chinese Character Calligraphy Elements}

As an artistic form, calligraphy is the treasure of traditional Chinese culture. Chinese calligraphy is an abstract art using ink brush to write Chinese characters with strong territoriality and nationality, pursing the beauty of lively spirit. Calligraphy has already been widely used as a unique visual form beyond its words connotation, and is playing the role that cannot be matched by other words and character style in packaging design of white spirit. While making wine packages, people can not only develop unique sense of form 
and visual effect using calligraphy, and meanwhile, they can also interpret connotation and cultural background utilizing the performance of calligraphy, inner beauty of calligraphic art and its artistic conception, emotional appeal, charm and character.

In actual packaging design, calligraphy cannot be simply carried into design for character style, yet the characteristic of commodity itself shall be taken into consideration, while paying attention to the coordinative relationship between words and other relevant elements. As for permutation and combination of words, the comparison and restriction between visual elements shall arouse attention, and the character style, size, structure and artistic style shall follow positioning style of the product to obtain harmony and unity of overall design. Calligraphy has been the most vivid finishing touch in packaging design of white spirit, playing important role of communication and exchange between product packaging and consumers.

\section{Reference Application of Traditional Classic Utensil Modeling}

The ancient Chinese excellent object modeling such as chinaware, bronze ware, lacquer ware, enamel vessels and large number of living appliances and so on are refined from the laboring life of ancestors, reflecting and representing the classic symbol of formative art of Chinese civilization. Those symbol elements may provide abundant references for today's design. Traditional Chinese modeling is of the solid, perfect, tensible style, which is simple yet elegant, rendering an atmosphere of bold and generous. Traditional Chinese modeling has always been praising for its rational function, graceful form, unique decoration and sense of beauty of oriental art. Designers have enriched the appearance of traditional modeling using modern design concept through transformation, breaking up, reorganization. Integrate those drinking vessels into modern white spirit packaging with innovation using modern packaging process and technology, broadening greatly the design thoughts of white spirit packaging, meanwhile the excellent history, culture and artistry of Chinese wine culture has been reflected as well, indicating strong cultural affinity.

\section{CONCLUSION}

Chinese civilization is of long standing, which makes the connotation of wine culture extensive and profound. Under the age of economic take-off and material wealth, and the increasing product homogeneity resulted by rapid development of white spirit industry, wine culture is the core competitiveness to obtain market shares both at home and abroad. Packaging is the direct "carrier of culture and material" to display wine culture. Make the internal quality of white spirit and the external appearance of the packaging complement each other through summary, understanding and mastering of wine culture and the skillful application of it in packaging design, enabling the character of white spirit and the solid wine culture to integrate as a unity.

\section{REFERENCES}

[1] $\mathrm{Xu}$ Shaohua. Chinese Wine and Traditional Culture [M].Beijing: China Light Industry Press, 2003.

[2] Bian Yijing, Fan Xijia. Chinese Wine Culture and Packaging Container of Wine [J]. Shanghai Packaging, 2004(4).

[3] He Manzi. Chinese Wine Culture [M]. Shanghai: Shanghai Guji Press, 2001

[4] He Jing, Han Huairen. Traditional Chinese Culture [M]. The People's Liberation Army Press, 2002.

[5] Luo Qiuming, Liu Anmin. Color, Emotion, Packaging [J]. Packaging Engineering, 2002 (1) 